\title{
Práticas artísticas em novas matrizes de subjetividade ou a internet como fator de fissuras no sistema da arte
}

\author{
MARIA AMÉLIA BULHÕES
}




\section{- RESUMO}

Análise da obra de artistas que, trabalhando em interação com a internet, apresentam novas matrizes de sensibilidade, atuando nas fissuras no sistema da arte contemporânea no Brasil. Exploramos três eixos dessa produção: o envolvimento com temas e comportamentos originários das práticas em rede, a utilização de uma visualidade advinda da e-imagem e o compromisso crítico social que assume problemáticas das notícias divulgadas nos meios de comunicação on-line. Destacamos o caráter pós-midiático dessas obras e sua inserção no circuito artístico, mais além da web arte.

\section{PALAVRAS-CAVE}

Pós mídia arte, sistema da arte, e-imagem, arte e internet no Brasil, arte contemporânea.

\section{ABSTRACT}

Analysis of the work of artists who, working in interaction with the internet, present new sensitivity matrices, acting in the fissures in the contemporary art system, in Brazil. From these works explore three axes of this production: the involvement with themes and behaviors originating from the network practices, the use of a visuality derived from the e-image and the critical social commitment that assumes problems of the news divulged in the online media. Highlight the post mediatic character of these works and their insertion in the artistic circuit, beyond the web art.

\section{KEYWORDS}

Post media art, art system, e-image, art and internet in Brazil, contemporary art.

Embora a internet tenha sido disponibilizada ao público recentemente (na segunda metade da década de 90) ela hoje faz parte do universo comunicacional mundial, transformando a forma de pensar e se relacionar, definindo novos valores e padrões de comportamento. Os trabalhos pioneiros de arte em rede são de 1996, produzidos por Olia Lialina e Vic Kosik, no Brasil, Celso Reeks e Thiago Boud'hors criaram, em 1997, Lands Beyond, considerado um dos iniciadores da web arte ${ }^{1}$ no País e reconhecido mundialmente. Ainda que emergindo precocemente, a prática da web arte no Brasil não se desenvolveu quantitativamente nem qualitativamente na proporção das práticas internacionais neste meio. $O$ caráter experimental da produção nacional, localizada fundamentalmente em espaços acadêmicos, restringiu seu alcance a um público menor e muito especializado, sem atingir o campo tradicional da arte nem o grande público da internet. A falta de apoio institucional, e mesmo empresarial, reduziu esta produção aos centros de pesquisa de arte e tecnologia.

Considera-se web arte trabalhos produzidos com ferramentas da internet e utilizando, preponderantemente este meio em sua difusão. 
A arte, como uma categoria de produtos e práticas sociais que se definem a partir de um "...conjunto de indivíduos e instituições responsáveis pela produção, difusão e consumo de objetos e eventos, por eles mesmos rotulados como artísticos, e, também, pela definição dos padrões e limites da Arte para uma sociedade, ao longo de um período histórico" (BULHÕES, 2014 p. 15), desde a sua instituição como campo, vem atuando na construção e na preservação de sua autonomia. $A$ arte contemporânea, entretanto, tem alargado os limites do campo artístico, com cruzamentos e hibridismos que problematizam e tencionam esta autonomia, levando alguns autores a falar em pós- autonomia ou heteronomia. Dentro desse novo âmbito da arte contemporânea deve-se considerar a presença de artistas que, usando múltiplas mídias disponíveis ${ }^{2}$, têm lidado com a internet em seu trabalho, abrindo um campo específico de problemáticas para a arte contemporânea.

Nos cruzamentos com esse dinâmico e complexo meio de comunicação, esses artistas conectam diversas realidades que coabitam o mundo atual, lidando com matizes de sensibilidade que operam fendas do sistema da arte. Ao exporem o meio on-line, lidam com uma nova subjetividade, que desestabiliza e ao mesmo tempo alimenta o campo artístico. Atuando de forma crítica na sociedade da cultura de massas, eles criam novos diálogos e possibilidades comunicacionais, e interagem com críticos, pois seus trabalhos são expostos em galerias e instituições museológicas, ganham prêmios, bolsas e entram no mercado

\section{A construção de um novo olhar: visualidades compartilhadas e em fluxo}

Como observou Pierre Bourdieu (BOURDIEU, 1989) ${ }^{3}$, a superação dos padrões clássicos de representação exigiu a construção de um novo olhar, e essa foi a grande mudança implementada pela modernidade em termos de artes visuais. De forma semelhante, acredito que a produção artística contemporânea promove profundas alterações na visualidade moderna, e as tecnologias digitais concorrem de forma significativa para que se estabeleça um novo regime escópico ${ }^{4}$. Este novo regime visual penetra profundamente no campo artístico, em diálogo com uma nova subjetividade que se desenvolve na sociedade contemporânea.

Muitos artistas que produzem seus trabalhos a partir dos recursos da internet trazem para o meio de arte a visualidade da e-imagem, com seus fluxos e instabilidades. Este é o caso de Giselle Beiguelman (1962, São Paulo/SP), com um trabalho explora intensamente imagens urbanas, captando os fluxos da cidade em seus diferentes aspectos. Em Paisagens Ruidosas (2013-2016), a artista realiza um processo de captura e edição de imagens no celular, em situações de trânsito nos mais variados contextos [aviões, salas de espera, táxis, aguardando ligações telefônicas etc.], com diferentes aplicativos: Satromizer, Glitch Lab, GLTCH, Glitché, entre outros. Produzida com diferentes modelos de iPhone, a série desdobra-se em diversas plataformas e formatos, Tumblr [Glitchorama], posts no Instagram e um

\footnotetext{
$\overline{2}$ Esses trabalhos que, mesmo em estreita conexão com a internet, saem do meio online para invadir diferentes espaços, são considerados por muitos autores Pós mídia arte.

${ }^{3} \mathrm{O}$ autor desenvolve essa idéia no texto $A$ Instituição da Anomia, publicado no livro O Poder Simbólico, Difel, Rio de Janeiro, 1989.

${ }^{4}$ Jose L. BREA utiliza esse termo no texto Cambios de Regime Escopico: Del Inconciente óptico a la E-image, in Estúdios Visuales, n.4, Madrid, enero 2007. 
arquivo no Flickr. Nestas diferentes plataformas é possível acompanhar o desenvolvimento do processo de trabalho. A série é um convite para enfrentar paisagens urbanas, partindo da desordem como paradigma essencial para sua fruição. Dois elevados - o Minhocão, em São Paulo, e a extinta Perimetral, no Rio - materializam o que ela define como "estética da obsolescência". Faz parte do projeto uma instalação em que se ouve o estampido da demolição da Perimetral, mas som e imagens estão dessincronizados.

A artista e o ruído, ou acidente, provocado pela defasagem dos registros no celular em relação aos programas usados para filmar e editar, incorporando a formação dessas fissuras visuais de nossa realidade, não mais integrada e harmoniosa como pretendia a concepção iluminista. A artista, que está inserida no sistema da arte, participando das bienais de SP e Bahia, de exposições em galerias e outras instituições artísticas como Galpão VB e Caixa Cultural, estabelece uma crise na visualidade moderna do circuito artístico. Entretanto, para se integrar nesse circuito, ela precisa sair do meio on-line e materializar suas imagens em diferentes meios, como impressão em jato de tinta sobre papel, backligts, videoinstalações, etc... Com suas paisagens urbanas, embebidas na estética do ruído e da obsolescência (glitch), promove com seu trabalho uma renovação na visualidade, assumindo a arte contemporânea.

Beiguelman, que se dedicou preponderantemente à web arte nos seus primeiros trabalhos, mesmo mantendo uma continuidade em sua produção, hoje insere-se em um fenômeno que se diferencia dos tempos heroicos, quando o uso da internet era algo underground e alternativo. Naquele momento ela se voltava para experiências comunicacionais, colocando-se como uma possibilidade de fuga dos controles alienantes da cultura de massas. Hoje, integrada como um novo paradigma da comunicação, a internet apresenta outros desafios aos artistas que, como Giselle buscam esse meio, conscientes de sua integração em ideologias e meios de controle dos grupos dominantes. Trabalhar nas fissuras do sistema da arte, evidenciando suas contradições frente a presença avassaladora dos novos meios comunicacionais, tem sido o caminho adotado. Bastante híbridas, essas propostas artísticas exploram as possibilidades tecnológicas e interativas e estabelecem conexões entre o mundo real e o mundo virtual de forma fluida, complexa e expandida a públicos mais amplos.

De forma semelhante, João Castilho (1978, Belo Horizonte/MG) trabalha a estética da internet se apropriando das imagens disponíveis na rede para elaborar seus trabalhos. Em Morte Súbita (2012), uma videoinstalação com nove canais em loop, 3'42", os vídeos são retirados da imprensa televisiva, no YouTube. Todos os vídeos envolvem situações de conflitos, em que a primeira camada é uma imersão em alguma cor do próprio vídeo, e a segunda é a situação em si. Os nove vídeos são colocados lado a lado, apresentando situações diferentes, que no final são alinhadas pela hora do tiro. $\mathrm{O}$ artista explora as inúmeras possibilidades criadas pela cultura open source que respondem às demandas da sociedade contemporânea, em busca de compartilhamento, em um mundo estereotipado e segmentado, onde os grandes relatos faliram. Ele, como muitos outros, realiza suas críticas a partir do estabelecimento de redes de interesse e de intercomunicação aberta. Sua prática artística inscreve-se no espaço coletivo que cria situações de experimentação e condições inéditas de recepção, respondendo à crise do autor com o fomento da 
inteligência distribuída. Em outro trabalho, Erupção (2013), realiza uma videoinstalação com seis TVs de tubo, seis media players, 4'23', em loop, em que novamente capta vídeos da internet, edita-os utilizando zooms, loops e cortes. Mostra vários ônibus queimando em São Paulo e outras cidades brasileiras, jogando com a ambiguidade do ato de queimar ônibus, que que pode ser visto tanto como um ato de terrorismo quanto como um ato insatisfação social, de reivindicação e protesto. Seu trabalho foge ao tipo mais tradicional de objeto artísticos, entretanto o artista já fez exposições nas galerias Celma Albuquerque e na Zipper, participou do projeto Rumos Itaú e de uma residência na FAAP, além de obter as bolsas Funarte e PampuIha. Assim, pode-se dizer que ele desenvolve uma forma de trabalho que se apropria da produção anônima disponibilizada na rede, incorporando seus temas e imagens ao circuito tradicional da arte.

Jose Luis Brea ${ }^{5}$, ao analisar o que ele denomina Cultura RAM, afirma que são as redes de conexão as responsáveis pela produção de conhecimento e não mais as estruturas de armazenamento de dados. Dessa forma, os inúmeros nós de circulação e transferência de informações que se observam na rede são os verdadeiros produtores da cultura. A sociedade da comunicação estabelece novas relações de trabalho e novas formas de estruturar o pensamento, e as artes visuais não estão fora desse debate. A cultura atual dirige-se a uma tendência eminentemente relacional, em que as práticas artísticas se tornam primordialmente políticas, abandonando o regime de mercado, para se integrar às novas economias de distribuição. A possibilidade de que qualquer indivíduo ou grupo, utilizando-se das tecnologias disponíveis, crie seu lugar de arte na rede, inserindo-se em um sistema de relações específicas, abre frestas nos controles sociais. O uso da internet é um meio de se apropriar das experiências do mundo atual, incorporando o cotidiano tecnológico em suas reflexões. Beiguelman e Castilho não se mantêm na rede on-line, extrapolam suas práticas para outras mídias artísticas mais aceitas pelas galerias e instituições. Com essas diferentes estratégias, eles ampliam as perspectivas comunicacionais de suas obras e, ao mesmo tempo, articulam possibilidades de obter reconhecimento dentro do sistema da arte.

\section{Os selfies, um fenômeno da cultura on-line que penetra no circuito artístico}

As instâncias de difusão, que no reconhecimento artístico desempenham um importante papel na contemporaneidade, se organizam em um circuito globalizado, que articula os críticos e curadores, assim como as instituições museológicas. Atores e instituições, juntos, constituem o discurso e o lugar oficial da arte. Tudo que é produzido, difundido, comentado e vendido como arte, em algum momento passa pelo reconhecimento de algumas dessas instâncias. A internet não é considerada um lugar de consagração de arte, entretanto nela têm se gestado novos valores e novos processos de circulação que, quando apropriados por artistas, abrem fissuras no circuito tradicional. Isso pode ser observado no uso dos selfies, autorretratos repetidamente postados nas redes sociais, que evidenciam uma cultura do Eu e da autoexposição, estimulada pela cultura da participação nos meios on-line. Esse

\footnotetext{
${ }^{5}$ BREA, Jose Luis. Cultura RAM. Gedisa, Barcelona, 2007.
} 
tema da cultura de massa vem sendo incorporado no circuito elitista da arte, de forma mais radical aos mais diluídos exemplos que podem ser encontrados.

Aleta Valente (1986) Rio de Janeiro/RJ, vive e trabalha no RJ, desenvolve uma obra que se alimenta especialmente de elementos da baixa cultura que se esparrama pela internet, desfrutando de um espaço de exposição do qual não disporia fora desse meio. Assim, em @ex_miss_febem (2015-2016), a artista criou um perfil fictício/avatar/personagem no Instagram, onde postava selfies do próprio corpo seminu. A artista usava para se retratar contextos urbanos da periferia do Rio de Janeiro, locais que escolhia para mostrar o cenário nada glamoroso da vida suburbana, ao contrário das cenas que costumam ser divulgadas como "cartõespostais" da cidade turística. Com essas imagens ela discute os limites do corpo feminino em exposição nas redes sociais, utilizando o celular como dispositivo e a plataforma como meio. $\mathrm{O}$ uso de imagens consideradas grosseiras ou mesmo agressivas aos valores morais tradicionais, inserindo um universo periférico e marginal, ocasionou que, no final de 2016, por denúncias de usuários incomodados com as imagens, seus perfis do Facebook e Instagram fossem bloqueados. Entretanto, a artista foi indicada ao Prêmio PIPA 2017, um dos tradicionais fóruns de reconhecimento do circuito artístico nacional, e, além disso, Valente participa de exposições em galerias. Neste caso em particular, apesar de a artista ter formação em artes visuais, ela se vale de uma tendência eminentemente relacional da comunicação on-line, em que as práticas culturais se tornam primordialmente políticas, abandonando o regime de mercado, para se integrarem às novas economias de distribuição. A possibilidade de que qualquer indivíduo ou grupo, utilizando-se das tecnologias disponíveis, crie seu lugar de arte na rede, inserindo-se em um sistema de relações específicas, abre frestas nos controles sociais.

Trabalhando de forma menos agressiva aos valores do status quo, mas bastante questionadora dos padrões de comportamento feminino, Laís Pontes (Fortaleza/CE, 1981), que vive e trabalha em Londres, desenvolveu o projeto Born Nowhere (2013-2016). São autorretratos feitos pela artista e modificados digitalmente, onde transforma suas feições construindo diferentes personalidades para si. $\mathrm{O}$ projeto, que pode ser relacionado ao trabalho de Cindy Sherman, ao discutir os estereotipados papéis da mulher na cultura de massa, utiliza plataformas de mídia sociais como base de interação para a construção de personagens virtuais. Assim, após a construção de uma nova autoimagem, ela convida os usuários do Facebook a compartilhar pensamentos e interpretações referentes à personagem publicada. $\mathrm{A}$ artista cria um ambiente de interação entre os seus personagens e os usuários da internet, que se tornam coparticipantes do projeto, abrindo para seu projeto possibilidades de experiência sem limitações socioculturais. Posteriormente, Pontes faz uma compilação dos comentários dos usuários participantes do Facebook e constrói uma biografia para sua personagem. As respostas dos usuários são influenciadas pelos estereótipos visuais de cada personagem (cabelo, maquiagem, roupa, postura etc..). A artista desencadeia o que os psicanalistas conceituam como "projeção", pois, com base em suas próprias memórias e experiências, o internauta tende a projetar o contexto em que ele próprio se insere, que ele mesmo vivencia, suas realidades e suas fantasias, e que a artista usa para construir seu personagem. Nos 
últimos anos, com o advento da web $2.0^{6}$ e das mídias locativas ${ }^{7}$, práticas participativas dos internautas vêm tomando um grande impulso, sendo muito usadas para os artistas realizarem seus experimentos poéticos. Neste trabalho, a artista vai revelando histórias íntimas e pessoais de cada participante, que terminam por se confundir com a própria estética da publicidade. Trata-se, portanto, de um projeto de interferência no espaço público por uma ação gerada a partir do ciberespaço. Em um processo coletivo, são redesenhados os intercâmbios do real com o imaginário. Pontes, com a exploração dessas novas ferramentas, abre questões bastante contundentes sobre identidade no mundo das selfies e das redes sociais.

Também trabalhando sobre selfies e o universo da autorrepresentação na internet, Felipe Cama (Porto Alegre/RS, 1970), que vive e trabalha em São Paulo, apresenta Imagens Surradas (2014), sob a forma de um vídeo de 4'33", composto por 2.773 selfies apropriadas do Instagram. As imagens passam rapidamente como flashes, de modo que não há como se concentrar em cada foto. Quanto mais o vídeo chega ao seu fim, mais as imagens se esvaecem, permitindo ver as camadas se sobrepondo e misturando.

A internet consolidou a visualidade do inacabado, com imagens que se desdobram no simples ato do usuário de clicar o mouse, que se processa pela sobreposição e alternância de camadas ou superfícies, sem que uma elimine a outra. Nenhuma imagem é permanente, mas está sempre em devir, deslocando a ideia de finalização e fechamento, pois uma página é captada em um momento e será outra no próximo, sempre em mutação. É um processo de adição que potencializa a comunicação e dinamiza o resultado, cuja visualidade Felipe Cama explora no campo da arte. Neste trabalho, o artista põe em xeque a possibilidade de individualidades na sociedade de massa, ao evidenciar a homogeneidade e o padrão dessas imagens. O que seria uma afirmação do Eu se mostra como uma preponderância do massivo, e a estética da internet invade o ambiente de museus e galerias, uma vez que Felipe Cama é representado pela galeria Leme, onde fez exposições individuais, e em seu currículo apresenta participações em mostras coletivas com curadorias de Emanuel Araújo, Felipe Chaimovich e Tadeu Chiarelli.

Esses artistas encontram na internet, uma realidade de nosso dia a dia, um mundo de alternativas em que é possível escolher caminhos e fazer descobertas. As diferentes conexões e os olhares compartidos que a rede possibilita ampliam o potencial de diálogo e de experiências ativas que essa arte pode estabelecer com os mais diferentes territórios, e que assim abrem frestas e impulsionam mudanças no sistema da arte.

A interatividade, prevista em alguns desses projetos, redefine os papéis do autor e do receptor, fazendo desaparecer a figura passiva do espectador. Isso porque, na maioria dos casos, não há um resultado previsível e controlado, e o desenvolvimento dos trabalhos depende, em grande parte, das decisões do usuário, a partir das inúmeras alternativas de trajetos propostos pelo artista, estabelecidos, a priori, na programação de software utilizada. O que faz esse tipo de proposta

\footnotetext{
$\overline{6}$ Termo criado em 2004, para designar um conjunto de serviços em plataforma, envolvendo aplicativos baseados em possibilidades de uso participativo sob forma de comunidades, sem a necessidade de um maior conhecimento das tecnologias da informação.

${ }^{7}$ Também conhecidas como mídias móveis, ou seja, equipamentos de comunicação que permitem seu uso em trânsito, como celulares, Iped, Ipod e outros.
} 


\section{Arte política perpassada pelos conteúdos dos meios de comunicação on-line}

A apropriação crítica de inúmeros conteúdos que circulam na internet, sem controle ou hierarquias, pode constituir modos de reagir aos processos de homogeneização que se verificam no âmbito da cultura de massa. Podem apresentar, ainda, agenciamentos que subvertem a ordem estabelecida, através de práticas de produção de visualidade que reclamam a dissolução das fronteiras hierárquicas da arte. Por fim, favorecem a criação de formas de subjetivação que oportunizam ao seu receptor desenvolver um questionamento dos modos e instrumentos de politização do espaço da visualidade, realizando experiências de socialização e produção de comunidade.

O desenvolvimento dos processos comunicacionais no mundo atual e a desterritorialização da indústria cultural são fatores importantes que influenciam a expansão sem precedentes do universo da arte que se vivencia hoje. Essa mudança qualitativa e quantitativa implicou alterações que trouxeram significativas redefinições do papel da arte num contexto social marcado por um crescimento acelerado da população e pela massificação da cultura. A experimentação de novas estratégias torna possível descobrir papéis políticos na visualidade contemporânea, comprometendo-se com seu espaço e seu tempo. São produções que emergem das tensões e contradições da sociedade, tentando responder aos desafios que esta lhes coloca, construindo uma visualidade que se atualiza constantemente com os avanços tecnológicos, mas que não deixa de se articular às realidades locais. Assim, a arte politicamente engajada, tão cara ao modernismo dos anos 1920, veste novas roupagens. Ela se apresenta no sistema da arte expondo conteúdos disponíveis em rede, trabalhando-os de forma a tensionar sentidos e reacender 0 papel crítico-social da arte.

Isso é o que faz Traplev (Roberto Moreira Junior, 1977, Caçador/SC), que vive em Recife, em seu trabalho alimentado pelas contradições dos discursos das mídias. Em Autorefletíveis (2015), ele apresenta uma coleção de frases e imagens, em dois vídeos em looping aleatório, em duas telas LCD no chão, encostadas verticalmente à parede, com duração aproximada de sete minutos. Elas foram selecionadas pelo artista através de um aplicativo de web. Foram selecionadas aproximadamente 50 frases geradas pelo app com o Facebook de Traplev. O artista posta muito sobre escândalos e a situação política junto com coisas banais (como a maioria dos usuários).

Em Equivalência absurda na sala 3 (2015), ele realiza instalações e intervenções utilizando uma seleção e a edição de conteúdos que sampleou (são imagens e manchetes) e que utiliza em diferentes dispositivos. Com informações da mídia massiva e outras notícias de contra-história e contracomunicação, expõe ideias e pensamentos de contravenção, crítica e registro do absurdo da realidade, expondo contradições do momento histórico no Brasil. De forma semelhante, em Retrato com e sem propina (2016), Traplev reage ao impulso das múltiplas manchetes que denunciavam as muitas delações e propinas dentro e fora do governo federal a partir de março de 2016. Ao realizar o registro e a edição desses conteúdos, o artista flagra o processo subliminar com que a mídia opera para defender seus interesses em uma campanha de desestabilização do governo que se mostrava parcial e duvidosa. Um outro projeto, Alfabeto Flúor, surgiu no impulso de registrar o 
momento histórico brasileiro a partir do ponto de vista da crítica e de reflexões que partem do princípio do questionamento a essa operação jurídica que inaugura um novo Estado de Exceção no Brasil, a partir de maio de 2016, com a votação no Congresso Nacional sobre o impedimento da presidenta da República, eleita democraticamente por mais de 54 milhões de eleitores brasileiros. Neste trabalho, as placas, contendo cerca de dez letras e ou números, podem ser manipuladas na parede. Em sua primeira versão ele foi exposto na forma de dois cavaletes contendo quatro letras e ou números, produzida para a exposição apresentada em agosto na Casa Triângulo, em São Paulo, e uma segunda versão do mesmo projeto foi produzida para sua exposição individual na Sé Galeria, em São Paulo. As intervenções começaram a ser produzidas a partir do contexto da crítica política em meados de abril de 2016. Compõem esse conjunto textos críticos de diversos autores como Eliane Brum, Vlademir Safatle, Leonardo Boff, entre outras fontes, como Wikipédia, Constituição Federal de 1988 etc. Em cada texto foi colocada uma letra ou um número aleatório na intenção de formar um alfabeto visual com números e outras formas e marcas gráficas.

O vácuo da informação é o corpo do trabalho do artista, que explora o inconsciente coletivo (político, social, cultural, artístico etc.) em termos de reflexões e ilusões. O trabalho reflete sobre os clichês de nossos tempos, trazendo-os para o campo estético. Com isso, mesmo fazendo permanecer a linguagem comunicacional dos novos meios, cobra do público posicionamentos em diversos níveis. Traplev traz para o sistema da arte essa problemática dentro de uma abordagem crítica que está modificando mentalidades dentro dele, uma vez que o artista já ganhou o prêmio Marcantonio Vilaça - PIPA, Bolsa Funarte, participou da Bienal do Mercosul e de importantes residências no Brasil e no exterior, além das exposições em galerias já anteriormente comentadas. Renova e atualiza, com a linguagem das mídias on-line, a prática da arte política.

\section{Considerações finais}

As bases da construção da autonomia do campo artístico foram bastante analisadas por Bourdieu, que estudou a formação deste na modernidade, entretanto a contemporaneidade nos coloca novos desafios. Evidenciam-se conexões com o mundo real e cruzamentos com diferentes áreas de conhecimento, o que levou alguns autores a apontar o que denominam pós-autonomia e ou heteronomia. Essa arte, que se mistura e se contamina, perde em autonomia para o campo, mas ganha expansão e penetração em outras áreas da sociedade. A internet, por seu intenso potencial de interferência em diferentes circunstâncias do mundo contemporâneo, ao fazer parte dos inúmeros fatores responsáveis por essa crise de autonomia, deve ser melhor observada. Neste estudo, o foco de análise está dado no contexto brasileiro, mas o mesmo está ocorrendo no âmbito internacional, e a escolha de artistas locais se deve ao fato de favorecer a identificação de suas conexões dentro de um cenário que nos é mais conhecido.

Nesta análise, apresentam-se as novas matrizes de sensibilidade com que lidam os artistas que trabalham a partir da internet, organizadas em torno de três grandes tendências: envolvimento com temas e comportamentos originários das práticas em rede, utilização de uma visualidade advinda da e-imagem e 
compromisso crítico social que assume problemáticas das notícias divulgadas nos meios de comunicação on-line. Essas matrizes podem ser observadas em trabalhos de artistas que, sempre ligados à internet, utilizam diferentes mídias e se incorporam ao sistema da arte, expondo em galerias e museus, ganhando prêmios e participando de inúmeras de suas instâncias. A questão que se coloca, entretanto, é sobre as possibilidades e limites dessas práticas em termos de interferir realmente no sistema da arte. As transformações que a disseminação da internet implementa no mundo contemporâneo apontam para uma possível democratização. O seu fácil acesso e as inúmeras possibilidades de explorar a conectividade favorecem manifestações coletivas, e suas flexibilidade e amplitude de ação possibilitam driblar os controles dominantes. Essa produção utiliza, desenvolve e estabelece novas formas de relação com o público, rompendo, de alguma maneira e dentro de certos limites, com as tradicionais hierarquias do sistema da arte. Entretanto, esse novo território é uma zona de risco. O artista e sua obra podem ter esvaziadas suas intenções mais radicais ao serem absorvidos pelo mercantilismo e o elitismo do sistema da arte, mas podem, pelo contrário, desenvolver uma arte mais participativa, excêntrica, pouco segura, que escapa na maioria das vezes ao controle social e à autoridade do sistema. Os desafios estão aí, criar é correr riscos.

\section{Referências}

BOURDIEU, Pierre. O poder simbólico. Rio de Janeiro: Difel, 1989

BREA, Jose Luis. Las três eras de la imagen. Madri, Akal, 2010

Cambios de regime escópico: del inconsciente óptico a la e-image, in Estudios Visuales, n4 Madrid, enero, 2007.

Cultura RAM. Barcelona, Gedisa, 2007

El tercer umbral: Estatuto de las praticas artisticas en la era del capitalismo cultural, Madrid,

CENDEAC, 2004.

BULHÕES, Maria Amélia; FETTER, Bruna; RAUPP, Bettina; ROSA, Nei Vargas. As novas regras do jogo: o sistema da arte no Brasil, P.Alegre, Zouk, 2014.

PRADA, Juan Martin. Outro tempo para el arte. Questiones y comentários sobre el arte actual, Madri, Sendemia, 2017.

Praticas artísticas e internet em la época de las redes sociales, Madri, Akal, 2015

Recebido em: 15/06/2017 - Aprovado em 21/08/2017 